\title{
Vaccine hesitancy in case of under-5 vaccination in slums of Burdwan Municipality, West Bengal: A cross-sectional study
}

\author{
Sayantani Nayak', Dilip Kumar Das ${ }^{2}$, Rupali Thakur ${ }^{3}$, Niladri Banerjee ${ }^{4}$ \\ ${ }^{1}$ Junior Resident (PGT), ${ }^{2}$ Professor and Head, ${ }^{3}$ Assistant Professor, ${ }^{4}$ Senior Resident, Department of Community \\ Medicine, Burdwan Medical College, Burdwan, West Bengal, India
}

Background: There are multiple reasons for which a considerable proportion of the population remains unvaccinated, including vaccine hesitancy. Identifying the reasons behind vaccine hesitancy, especially in marginalized population, is essential. Aims and Objectives: The aims of the study were to estimate the magnitude and determinants of vaccine hesitancy related to under-5 vaccination in slums of Burdwan Municipality, West Bengal. Materials and Methods: A community-based descriptive study with cross-sectional design was conducted between September 2020 and January 2021 among 135 study subjects (under- 5 children) selected by multistage random sampling. Data were collected by interviewing the primary caregivers of selected children using a predesigned schedule including vaccine hesitancy survey questionnaire by Strategic Advisory Group of Experts. Data analysis was done using SPSS v.20. Results: Vaccine hesitancy was found in case of $11.9 \%$ of the study subjects. Refusal was seen in $2.2 \%$, only in case of birth doses, whereas hesitancy due to delay was seen in $9.7 \%$ in case of MR, JE, DPT, and OPV boosters. Stated reasons for hesitancy were - "vaccine was not needed" (47.4\%), "fear of needles" (31.5\%), and "not able to leave other work at home" $(21.1 \%)$. Caregivers of $17 \%$ of the study subjects faced difficulty from getting their child immunized mainly due to timing of the clinic and lockdown. The presence of vaccine hesitancy was not associated with sociodemographic characteristics of the child or of the caregivers. Conclusion: Vaccine hesitancy was found to be low in the study area, it was mainly to birth doses and mostly due to lack of awareness among caregivers.
Access this article online

Website:

http://nepjol.info/index.php/AJMS

DOI: 10.3126/ajms.v13i2.40880

E-ISSN: 2091-0576

P-ISSN: 2467-9100

Copyright (c) 2022 Asian Journal of Medical Sciences

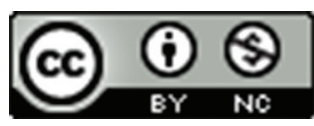

This work is licensed under a Creative Commons Attribution-NonCommercial 4.0 International License.

Key words: Burdwan municipality; Slums; Under-5 children; Vaccine Hesitancy;

West Bengal

\section{INTRODUCTION}

One of the most cost-effective intervention for the prevention of diseases is vaccination which has successfully played a major role in eradication, elimination, and control of communicable diseases. ${ }^{1}$ When vaccination is widely accepted in a community, it provides both direct protection at individual level and indirect protection through herd immunity in a community by affecting transmission of vaccine preventable diseases, thereby reducing risk of infection to susceptible individuals. ${ }^{2}$ One of the major reasons behind endemicity and resurgence of certain vaccine preventable diseases such as measles, poliomyelitis, and pertussis is under-vaccinated and unvaccinated communities in many developed and developing countries. ${ }^{3}$

The World Health Organization (WHO) Strategic Advisory Group of Experts (SAGE) on immunization has defined vaccine hesitancy as delay in acceptance or refusal of vaccines despite availability of vaccine services. Vaccine hesitancy is complex and context specific, varying across time, place, and candidate vaccines. It is influenced by factors such as complacency, convenience, and confidence. It is seen that "Vaccine attitudes" can be seen on a spectrum ranging from total acceptance to complete refusal. Vaccine hesitant individuals are a heterogeneous group in the middle of 
this spectrum. They may refuse some vaccines, while agree to others; they may delay vaccines or accept vaccines but are unsure while doing so. It is estimated that $<10 \%$ of individuals have strong anti-vaccination convictions. ${ }^{4}$ However, a more significant proportion could be categorized as being hesitant regarding vaccination. Knowledge gap regarding safety and/or efficacy of vaccines, especially newer vaccines, can affect parental decisions to vaccinate their child. ${ }^{5}$ This complex decision-making related to acceptance of vaccine is also driven by an admixture of scientific, psychological, economic, political, and sociocultural reasons. ${ }^{6}$

Therefore, acknowledgment and identification of the type of population who are vaccine hesitant and to find an estimate of the burden and to understand the problems in-depth related to vaccine hesitancy along with its determinants are needed. In November 2011, SAGE noted the negative impacts of vaccine hesitancy in both developed and developing countries. ${ }^{78}$ With this background, this study aimed to estimate the magnitude of vaccine hesitancy for available vaccines in case of under- 5 children residing in slums of Burdwan Municipality and to find out factors contributing to vaccine hesitancy among them.

\section{Aims and objectives}

The aims of the study were to estimate the magnitude of vaccine hesitancy for available vaccines among parents of under- 5 children residing in slums of Burdwan Municipality and to find out factors contributing to vaccine hesitancy among them.

\section{MATERIALS AND METHODS}

\section{Study design, setting, and duration}

This community-based cross-sectional study was conducted in slums of Burdwan Municipality, Purba Bardhaman District, West Bengal between September 2020 and January 2021.

\section{Study population}

Children of 1-59 months of age, residing in the study area for the past 3 months before data collection, were the study population. Mothers/caregivers of the aforesaid children were the primary respondents. Mothers unwilling to participate or absent during the day of visit or severely ill were excluded from the study.

\section{Sample size and sampling technique}

Considering prevalence of vaccine hesitancy among families of under- 5 children as $83 \%$ based on a previous study done at North Bengal, 9 95\% confidence interval and relative allowable error of $10 \%$; using the formula the $N=\frac{Z_{\alpha}{ }^{2} \times P \times(100-P)}{L^{2}}$ minimum calculated sample size comes out to be 79. Further considering design effect of 1.5 for the sampling method adopted, the required sample size was 118 . Anticipating $10 \%$ non-response, the final sample size was 132 .

The sampling was done in two stages - at first, $10 \%$ of the total number of slums, that is, $14.4 \sim 15$ slums were selected from 144 slums by simple random sampling; then from each slum, 132/15 9 households having at least one under- 5 children were selected by simple random sampling from a sampling frame created with the help of health workers working in that slum. Thus, a total of $15^{*} 9=135$ children each from one household were sampled.

\section{Data collection, tools, and technique}

The selected households in the slums were visited for interview. The youngest child of the family was chosen as the study subject. The primary caregiver, most preferably the mother, was interviewed using a predesigned pretested schedule consisting of questions regarding sociodemographic characteristics and validated version of vaccine hesitancy survey questionnaires version 1.0 developed by the WHO SAGE working group on vaccine hesitancy. ${ }^{8}$ Reviewing of immunization cards of under- 5 children was also done.

\section{Data analysis}

Collected data were entered into MS Excel, cleaned, and were imported into SPSS (V.23). Outcome variables, that is, presence of vaccine hesitancy, type of hesitancy (refusal/ delay), and type of vaccine toward which hesitancy is present were presented in the form of tables and figures. Sociodemographic characteristics were taken as variables to describe characteristics of the study population and to find out associations with the outcome variables by Fisher's exact test. Multivariable logistic regression was done to predict the presence of vaccine hesitancy from background variables.

\section{RESULTS}

A total of 135 households were included in the study as none of the eligible parents withheld consent to participate in the survey. About $53.3 \%$ of the children were male and $46.7 \%$ were female. About $4.4 \%$ were in the age group of $<12$ months, $13.3 \%$ in $12-23$ months, and $82.2 \%$ belonged to the age group of $24-59$ months. Mean (SD) age of the study participants was 34.17 (11.88) months. All of the caregivers were female; $21.5 \%$ among them were below 20 years of age, $74.0 \%$ of them were within $20-30$ years, and $4.5 \%$ were above 30 years. About $8.1 \%$ of the caregivers were found to be illiterate and informal literate. About $42.2 \%$ of them obtained primary school education, $15.6 \%$ obtained middle 
school education, and $34.1 \%$ obtained secondary school education and above. About $54.1 \%$ of the caregivers were living in joint families and $45.9 \%$ were living in nuclear families. About $11.9 \%$ of the families belonged to the upper middle and middle class, $65.2 \%$ belonged to the lower middle class, and $23.0 \%$ belonged to the lower class $^{10}$ (Table 1).

Vaccine hesitancy was found in case of 16 children (11.9\%) whereas refusal was noted in case of 3 children $(2.2 \%)$. The refusals were found to be toward birth dose of BCG, OPV, and hep. B. Vaccine hesitancy was found in case of 1.5\% of children toward MR and JE vaccines, in 4.4\% toward DPT booster, and in $0.7 \%$ toward OPV booster (Figure 1).

The most common reason for hesitancy was that their parents thought that it was not needed (47.4\%) followed by fear of needle $(31.5 \%)$ and difficulty to leave other work at home for taking their child to vaccinate (21.1\%). Factors that caused difficulty for the caregivers from getting their child immunized were mainly timing of clinic and lockdown imposed during COVID-19. Almost all leaders (religious, political, teachers, and health care workers) in their community supported vaccines for infants and children (Table 2).

Table 2 shows relationship between sociodemographic factors and presence of vaccine hesitancy, where, it was not found to be significantly associated with age of the child $(\mathrm{P}=0.861)$, gender of the child $(\mathrm{P}=0.776)$, caregivers' age $(\mathrm{P}=0.516)$ or educational status $(\mathrm{P}=0.630)$, family type $(\mathrm{P}=0.596)$, and socioeconomic status $(\mathrm{P}=0.432)$. Furthermore, no specific sociodemographic characteristics were found to have higher odds for vaccine hesitancy.

\section{DISCUSSION}

This study estimated that $11.9 \%$ of under- 5 children residing in slums of Burdwan Municipality were affected by vaccine hesitancy for one or more of the locally available vaccines. The global scenario of vaccine hesitancy is somewhat similar with wide variability but various studies reported prevalence of vaccine hesitancy ranging between $1.1 \%$ and $83 \%$ among specified population using the same screening tool. Several studies from Guatemala, Chennai, West Bengal, and Odisha hint about the increasing awareness and positive beliefs of parents about child vaccination. ${ }^{11-15} \mathrm{In}$ a similar study at Chennai, in a predominantly urban, educated, and working class population, the prevalence of vaccine hesitancy was $21 \% .{ }^{12}$ However, all the children had received complete vaccination appropriate for age. The major drivers for vaccine hesitancy were suspicions about newer vaccines, concerns about adverse effects of vaccines, and the perception that there is no need for vaccines against uncommon diseases. ${ }^{16}$ Understanding the three As (Awareness, Access, and Acceptability) dimensions of vaccine hesitancy in Odisha

\begin{tabular}{|c|c|c|c|c|c|}
\hline Descriptive characteristics & $\begin{array}{l}\text { Frequency } \\
\text { (\%) }\end{array}$ & $\begin{array}{l}\text { Vaccine hesitancy } \\
\text { frequency }(\%)\end{array}$ & $\begin{array}{c}\text { Chi-square test } \\
\text { P-value }\end{array}$ & $\begin{array}{l}\text { Adjusted OR } \\
(95 \% \mathrm{Cl})\end{array}$ & $P$ value \\
\hline \multicolumn{6}{|l|}{ Age of the child (months) } \\
\hline$<12$ & $6(4.4)$ & $1(16.7)$ & \multirow[t]{3}{*}{0.861} & Ref. & - \\
\hline $12-23$ & $18(13.3)$ & $2(11.1)$ & & $0.38(0.02-7.66)$ & 0.525 \\
\hline $24-59$ & $111(82.2)$ & $13(11.7)$ & & $0.59(0.04-8.08)$ & 0.690 \\
\hline \multicolumn{6}{|l|}{ Sex of the child } \\
\hline Male & $72(53.3)$ & $8(11.1)$ & \multirow[t]{2}{*}{0.776} & Ref. & \multirow[t]{2}{*}{0.453} \\
\hline Female & $63(46.7)$ & $8(12.7)$ & & $1.55(0.48-4.97)$ & \\
\hline \multicolumn{6}{|l|}{ Age of the caregiver (years) } \\
\hline$<20$ & $17(12.6)$ & $3(17.6)$ & \multirow[t]{3}{*}{0.516} & Ref. & 0.627 \\
\hline $20-30$ & $112(83.0)$ & $13(11.6)$ & & $0.46(0.09-2.20)$ & 0.334 \\
\hline$>30$ & $6(4.4)$ & $0(0.0)$ & & $0(0.0)$ & 0.999 \\
\hline \multicolumn{6}{|l|}{ Educational status of the caregiver } \\
\hline Illiterate and Informal literate & $11(8.1)$ & $2(18.2)$ & \multirow[t]{4}{*}{0.631} & Ref. & 0.338 \\
\hline Primary & $57(42.2)$ & $5(8.8)$ & & $0.36(0.05-2.43)$ & 0.296 \\
\hline Middle & $21(15.6)$ & $0(0.0)$ & & $0(0.0)$ & 0.998 \\
\hline Secondary and above & $46(34.1)$ & $9(19.6)$ & & $1.15(0.19-7.25)$ & 0.876 \\
\hline \multicolumn{6}{|l|}{ Type of family } \\
\hline Joint & $73(54.1)$ & $10(13.7)$ & \multirow[t]{2}{*}{0.596} & Ref. & \multirow[t]{2}{*}{0.557} \\
\hline Nuclear & $62(45.9)$ & $6(9.7)$ & & $0.69(0.19-2.42)$ & \\
\hline \multicolumn{6}{|l|}{ Socioeconomic status ${ }^{*}$} \\
\hline Upper-middle and middle class & $16(11.9)$ & $3(18.8)$ & \multirow[t]{3}{*}{0.432} & Ref. & 0.340 \\
\hline Lower-middle class & $88(65.2)$ & $11(12.5)$ & & $0.37(0.07-1.88)$ & 0.230 \\
\hline Lower class & $31(23.0)$ & $2(6.5)$ & & $0.19(0.02-1.84)$ & 0.155 \\
\hline
\end{tabular}




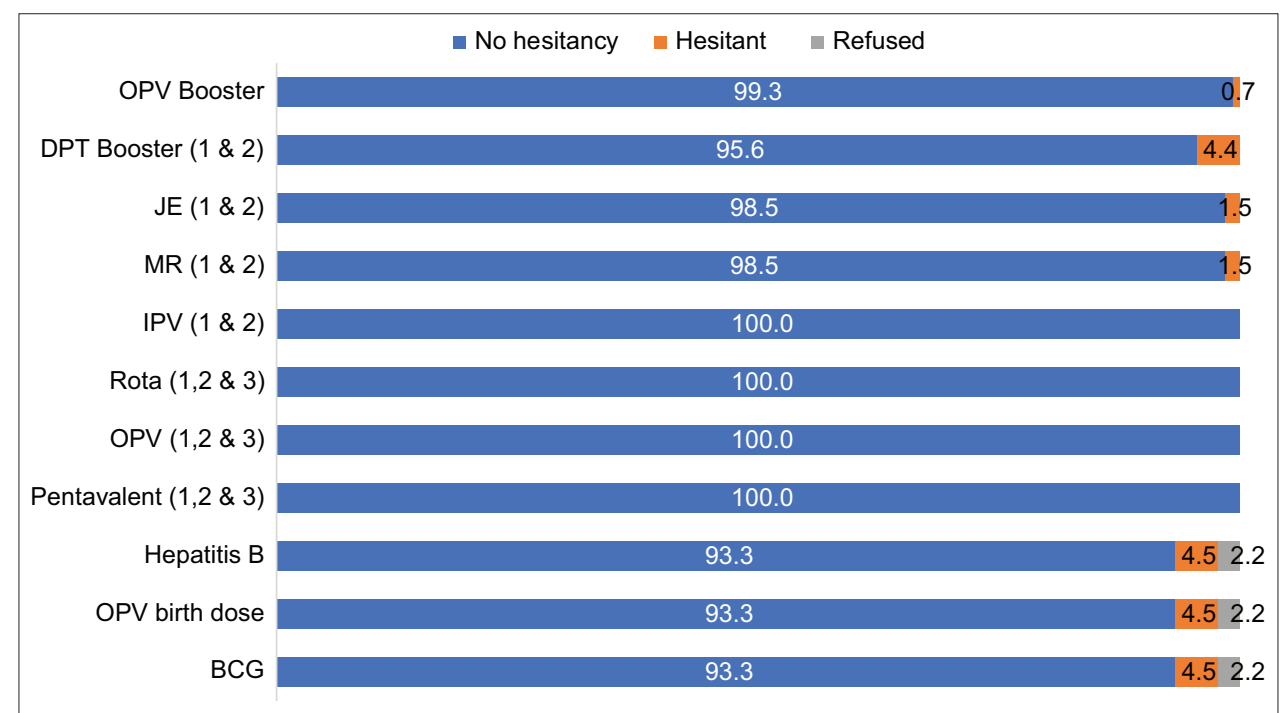

Figure 1: Vaccine hesitancy toward candidate vaccines $(n=135)$

\begin{tabular}{|c|c|c|c|}
\hline Descriptive characteristics & \multicolumn{3}{|c|}{ Frequency (\%) } \\
\hline \multicolumn{4}{|l|}{ Reasons for hesitancy $(n=16)$} \\
\hline Not possible to leave other work at home & & $3(18.7)$ & \\
\hline Fear of needles & & $6(37.5)$ & \\
\hline Did not think it was needed & & $7(43.8)$ & \\
\hline \multicolumn{4}{|l|}{$\begin{array}{l}\text { Caregivers facing difficulty from getting their child } \\
\text { immunized }\end{array}$} \\
\hline Did not face any difficulty & & $104(83.0)$ & \\
\hline Faced difficulty & & $23(17.0)$ & \\
\hline Timing of clinic & & $14(60.9)$ & \\
\hline Lockdown & & $17(73.9)$ & \\
\hline \multirow[t]{2}{*}{ Support of vaccination of children by local leaders } & Yes & No & Don't know \\
\hline & No (\%) & No $(\%)$ & No $(\%)$ \\
\hline Religious & $123(91.1)$ & $1(0.75)$ & $11(8.14)$ \\
\hline Political & $120(88.9)$ & $0(0.0)$ & $15(11.1)$ \\
\hline Teachers & $124(91.8)$ & $0(0.0)$ & $11(8.14)$ \\
\hline Health care worker & $135(100)$ & $0(0.0)$ & $0(0.0)$ \\
\hline
\end{tabular}

used the same tool in a sample of 260 households, selected from 30 clusters, and found that all the households knew that vaccines protect against infectious diseases and parents should vaccinate their children against all recommended vaccines and only $2 \%$ were not aware of them. ${ }^{13}$ Around $11 \%$ of parents highlighted long distance as an important barrier to vaccine uptake. They cited that due to lack of vaccine clinic in their village, they had to travel to another village, which is quite far. Parents informed that they had to wait for long hours at times and it had happened that they returned without vaccination. Nearly, $28 \%$ of parents had heard negative information about the vaccines, and despite hearing negative information, more than three-fourth parents took their children to vaccination. A similar study done in a slum setting of Siliguri, West Bengal, found that majority of $83 \%$ of the families were vaccine hesitant and only $17 \%$ were not hesitant. ${ }^{14}$ Nuclear families and mothers of lower educational status had significantly higher odds of vaccine hesitancy. Reluctance to vaccinate $(26.1 \%)$ and to be unaware/having no reliable information (20.5\%) were the major reasons cited for vaccine hesitancy.

In our study, the refusals were found to be toward birth dose of BCG, OPV, and hep. B. Vaccine hesitancy was found in case of $1.5 \%$ of children toward MR and $\mathrm{JE}$ vaccines, in $4.4 \%$ toward DPT booster, and in $0.7 \%$ toward OPV booster. Pentavalent and measles were more commonly refused or hesitated vaccines by the parents compared to BCG or polio. ${ }^{12}$ There was refusal mainly in case of birth dose of OPV, BCG, and hepatitis B, mainly due fear of needle and some thought that it was not needed so early in life. ${ }^{16}$ Refusals were found more in case of non-governmental institutional deliveries which were deficient in infrastructural provision for birth dose of vaccines. Hence, awareness from service providers and responsibility to inform 
mothers regarding birth doses followed by subsequent doses is necessary. ${ }^{9}$

The study held at Odisha found that long distances and time are the two prime factors of accessibility linked with the refusal or hesitancy of the vaccine. ${ }^{13}$ The study held at Chennai found that there is a high level of acceptance of vaccines at the level of parents and more than threefourths took their children for vaccination despite hearing negative information about them. ${ }^{12}$ A study in Siliguri, West Bengal, found that nuclear families and mothers of the lower educational status had significantly higher odds of vaccine hesitancy. ${ }^{14}$ Reluctance to vaccinate $(26.1 \%)$ and to be unaware/having no reliable information $(20.5 \%)$ were the major reasons cited for vaccine hesitancy. ${ }^{17,18}$ There are many different subpopulations of individuals with divergent reasons for not vaccinating or delaying vaccines. ${ }^{19,20}$ This may be due to a variety of factors, including complacency (low-risk perceptions of vaccine-preventable diseases), lack of convenient access to vaccine services, or lack of confidence in vaccines due to concerns about safety and other vaccine issues. ${ }^{21-23} \mathrm{In}$ our present study, the most of the people knew that vaccines protect against infectious diseases and recommended vaccination for their children. In contemporary studies, it has been stated that a large number of children could not complete their immunization schedules because health services do not regularly reach them. ${ }^{21}$ However, in our study area, universal immunization program is run routinely with dedicated health care workers who not only give the services regularly but also spread awareness about it to increases the acceptability. Other reasons for increased awareness about vaccines among parents could be widespread use of social media, mass media, and use of celebrities for mass awareness campaigns. All of the caregivers considered that vaccines can protect children from serious diseases and most wanted their children to be vaccinated with all the recommended vaccines. No ethnic or religious groups in the studied community had adverse idea regarding vaccination for their children. Almost all leaders (religious, political, teachers, and health care workers) in their community supported vaccines for infants and children. There was no internal or external pressure for not getting their children vaccinated.

Other studies found out mainly timing and distance of the clinic being a major reason behind vaccine hesitancy. ${ }^{13,14}$ In our study, we found out that, some of them have been reluctant or hesitated to get a vaccination for their child, major reasons behind them were fear of needles, timing of clinic, difficulty to leave work, or had some other work at home. Lockdown due to COVID-19 and associated difficulties such as unavailability of transport and also unawareness that immunization clinic was running even during lockdown added to it. Good educational status (most of them were literate) and proximity of vaccination center, rigorous implementation of various health programs which included immunization, and continuous IEC activities regarding vaccination by health workers, resulted in good vaccination coverage in this area. In congruence, vaccine coverage in India has improved from $44 \%$ to $62 \%$ over a period of 10 years (2006-2016). ${ }^{19}$

In our study, no such association between sociodemographic characteristics with vaccine hesitancy was found may be due to low prevalence of vaccine hesitancy in the study population. The findings of the study may be limited by the fact that the anticipated prevalence of vaccine hesitancy, which was used to calculate the sample size, is much more than resultant prevalence of vaccine hesitancy.

\section{Limitations of the study}

The findings of the study may be limited by the fact that the anticipated prevalence of vaccine hesitancy, which was used to calculate the sample size, is much more than resultant prevalence of vaccine hesitancy.

\section{CONCLUSION}

The prevalence of vaccine hesitancy among under-5 children was found to be low in slums of Burdwan Municipality although there is the presence of refusals among caregivers mainly in case of birth doses and delay due to fear of needles. Private maternity homes need to strengthen their infrastructure to provide birth doses of vaccines in time.

\section{ACKNOWLEDGMENT}

We gratefully acknowledge the health workers of Burdwan Municipality who helped in data collection. We are grateful to all mothers/caregiver for their support and cooperation.

\section{REFERENCES}

1. Centers for Disease Control and Prevention (CDC). Ten great public health achievements-United States, 1900-1999. MMWR Morb Mortal Wkly Rep. 1999;48(12):241-243.

2. Fine $P$, Eames $K$ and Heymann DL. "Herd immunity": A rough guide. Clin Infect Dis. 2011;52(7):911-916.

https://doi.org/10.1093/cid/cir007

3. Bramadat P. Human vaccines and immunotherapeutics. Landes Biosci. 2013;9(8):1763-1773.

4. Weekly Epidemiological Record Relevé Épidémiologique Hebdomadaire, 7 January 2011, 86 th Year/7 Janvier 2011, 86e Année No. 1-2, 2011, 86, 1-16; 2020. Available from: http://www. who.int/wer [Last accessed on 2020 Mar 14].

5. MacDonald NE. Vaccine hesitancy: Definition, scope and determinants. Vaccine. 2015;33(34):4161-4164. 
https://doi.org/10.1016/j.vaccine.2015.04.0360

6. Larson HJ, Cooper LZ, Eskola J, Katz SL and Ratzan S. Addressing the vaccine confidence gap. Lancet. 2011;378:526-535.

\section{https://doi.org/10.1016/s0140-6736(11)60678-8}

7. World Health Organization. Weekly Epidemiological Record, 2019. Vol. 94.Geneva:World Health Organization;2019. Available from: https://www.apps.who.int/iris/handle/10665/324920 [Last accessed on 2020 Mar 14].

8. Report of the Sage Working Group on Vaccine Hesitancy; 2014. Available from: https://www.who.int/immunization/sage/ meetings/2014/october/1 report working group vaccine hesitancy_final.pdf [Last accessed on 2020 Mar 14].

9. Barman D and Dutta A. Access and barriers to immunization in West Bengal, India: Quality matters. J Health Popul Nutr. 2013;31(4):510-522.

https://doi.org/10.3329/jhpn.v31i4.20050

10. Sharma R. Online Interactive Calculator for Real-Time Update of the Prasad's Social Classification; 2020. Available from: https://www. prasadscaleupdate.weebly.com [Last accessed on 2020 Mar 15].

11. Domek GJ, O'Leary ST, Bull S, Bronsert M, Contreras-Roldan IL, Ventura GA, et al. Measuring vaccine hesitancy: Field testing the WHO SAGE working group on vaccine hesitancy survey tool in Guatemala. Vaccine. 2018;36(35):5273-5281.

https://doi.org/10.1016/j.vaccine.2018.07.046

12. Narayanan SS, Jayaraman A and Gopichandran V. Vaccine hesitancy and attitude towards vaccination among parents of children between $1-5$ years of age attending a tertiary care hospital in Chennai, India. Indian J Community Fam Med. 2018;4(2):31. https://doi.org/10.4103/2395-2113.251436

13. Sharma S, Akhtar F, Singh RK and Mehra S. Understanding the three as (awareness, access, and acceptability) dimensions of vaccine hesitancy in Odisha, India. Clin Epidemiol Glob Health. 2019;8(2):399-403.

https://doi.org/10.1016/j.cegh.2019.09.010

14. Dasgupta P, Bhattacherjee S, Mukherjee A and Dasgupta S. Vaccine hesitancy for childhood vaccinations in slum areas of Siliguri, India. Indian J Public Health. 2018;62(4):253. https://doi.org/10.4103/ijph.ijph_397_17

15. WHO. Immunization Coverage. WHO Fact Sheet. Geneva: WHO
2021. Available from: https://www.who.int/news-room/fact-sheets/ detail/immunization-coverage [Last accessed on $2021 \mathrm{Mar}$ 10].

16. Poland GA and Spier R. Fear, misinformation, and innumerates: How the Wakefield paper, the press, and advocacy groups damaged the public health. Vaccine. 2010;28(12):2361-2362 https://doi.org/10.1016/j.vaccine.2010.02.052

17. Hagood EA and Herlihy SM. Addressing heterogeneous parental concerns about vaccination with a multiple-source model: A parent and educator perspective. Hum Vaccin Immunother. 2013;9(8):1790-1794.

https://doi.org/10.4161/hv.24888

18. Poltorak M, Leach M, Fairhead J and Cassell J. 'MMR talk' and vaccination choices: An ethnographic study in Brighton. Soc Sci Med. 2005;61(3):709-719.

https://doi.org/10.1016/j.socscimed.2004.12.014

19. Priya P K, Pathak VK and Giri AK. Vaccination coverage and vaccine hesitancy among vulnerable population of India. Hum Vaccin Immunother. 2020;16(7):1502-1507. https://doi.org/10.1080/21645515.2019.1708164

20. Waisbord $S$ and Larson $H$. Why Invest in Communication for Immunization: Evidence and Lessons Learned. A Joint Publication of the Health Communication Partnership Based at Johns Hopkins Bloomberg School of Public Health/ Center for Communication Programs (Baltimore) and the United Nations Children's Fund, New York; 2005. Available from: https://www.who.int/immunization/hpv/communicate/ why_invest_in_communication_for_immunization_unicef_ healthcommunicationspartnership_path_usaid.pdf?ua $=1$ [Last accessed on 2021 Mar 05].

21. Dubé E, Laberge $C$, Guay M, Bramadat P, Roy R and Bettinger J. Vaccine hesitancy: An overview. Hum Vaccin Immunother. 2013;9(8):1763-1773. https://doi.org/10.4161/hv.24657

22. Wilson SL and Wiysonge $C$. Social media and vaccine hesitancy. BMJ Glob Health. 2020;5(10):e004206. https://doi.org/10.1136/bmjgh-2020-004206

23. Rossen I, Hurlstone MJ and Lawrence C. Going with the grain of cognition: Applying insights from psychology to build support for childhood vaccination. Front Psychol. 2016;7:1483. https://doi.org/10.3389/fpsyg.2016.01483

\section{Authors Contribution:}

SN, DKD, and RT- Concept and design of the study, prepared first draft of manuscript; SN- Interpreted the results; reviewed the literature, and manuscript preparation; NB-Concept, coordination, statistical analysis and interpretation, preparation of manuscript, and revision of the manuscript.

Work attributed to:

Burdwan Medical College, Burdwan - 713 104, West Bengal, India

Orcid ID:

Dr. Sayantani Nayak- (D https://orcid.org/0000-0002-9984-7898

Dr. Dilip Kumar Das- (D) https://orcid.org/0000-0002-3027-0728

Dr. Rupali Thakur- (1) https://orcid.org/0000-0001-7983-243X

Dr. Niladri Banerjee- (D) https://orcid.org/0000-0001-5980-4343

Source of Support: None, Conflicts of Interest: None. 